METALLURGY AND FOUNDRY ENGINEERING - Vol. 36, 2010, No. 2

Dariusz Kopyciński*, Józef Dorula**

\title{
THE INFLUENCE OF IRON POWDER AND DISINTEGRATED STEEL SCRAP ADDITIVES ON THE SOLIDIFICATION OF CAST IRON
}

\section{INTRODUCTION}

Inoculation is nowadays a commonly applied metallurgical treatment carried out by foundries to improve the mechanical properties of commercial alloys. The essence of the cast iron inoculation consists in changing the physico-chemical state of molten metal. The change is obtained by introducing to the cast iron of low graphite nucleation power, shortly before mould pouring, a small amount of inoculant, that is, of a compound capable of increasing the number of active nuclei.

In metalcasting practice, the main criterion used in evaluation of the inoculation effect are changes in the mechanical properties of cast iron along with its chilling tendency. From a review of literature [1-9] it follows that the effectiveness of cast iron inoculation is in prevailing part evaluated from a change in: number of eutectic grains (increase), undercooling degree during eutectic solidification (decrease), character of metallic matrix (pearlitic matrix with varied degree of dispersion), characteristic of graphite precipitates (interdendritic graphite disappears in favour of the graphite of a uniform distribution).

It seems logical that quite often in technical literature [1-9] an increase in the tensile strength $R_{m}$ of inoculated cast iron is related to changes in the characteristic of graphite precipitates. The said relationship can be explained by the fact that due to inoculation the distance between the graphite flakes (and the length of these flakes) in the grains of the graphite eutectic are increasing. In this case, an effective inoculation treatment of (slightly hypoeutectic) cast iron will change the graphite distribution from interdendritic of type D (acc. to PN-EN ISO 945) into a uniform of type A. On the other hand, in strongly hypoeutectic cast iron in which numerous primary austenite grains are crystallising, an interdendritic graphite distribution of type E (acc. to PN-EN ISO 945) is usually obtained. Hence it

* Ph.D., D.Sc., ** M.Sc.: Faculty of Foundry Engineering, AGH University of Science and Technology, Kraków, Poland; e-mail: djk@agh.edu.pl 
follows that the character of graphite precipitates depends on interrelations between the interfacial distance of eutectic grains and interdendritic distance of primary austenite. Therefore it should be assumed a priori that the inoculation treatment will also have an important effect on the number and shape of the dendrites of primary austenite. In this study an attempt has been made to interrelate the effect of inoculant with the type of primary austenite precipitates and sulphur content in alloy. It is the fact commonly known that foundries often fail in obtaining the standard mechanical properties of grey cast iron when the content of sulphur in metallic charge is too low. Then the structure of castings is observed to hold a large number of the interdendritic graphite precipitates, the fact that greatly contributes to the ferritisation of cast iron matrix (small interlamellar spacing).

\section{METHODS OF INVESTIGATION}

Experiments were carried out in a medium-frequency induction furnace with $15 \mathrm{~kg}$ capacity crucible. Metallic charges were composed of "Sorel" pig iron, steel scrap, commercially pure silicon, ferromanganese and sulphur. Cast iron was inoculated with SB5 inoculant added in the amount of (\% wt.) $0.4 \%$, introducing additionally iron powder $0.4 \%$, and disintegrated steel scrap $-0.4 \%$. Chemical analyses of melts were made on a HILGER spectrometer. An average chemical composition of the investigated cast iron was: $2.90 \% \div 3.10 \% \mathrm{C}, 1.85 \% \div 2.05 \% \mathrm{Si}, 0.45 \% \div 0.55 \% \mathrm{Mn}, 0.01 \% \div 0.02 \% \mathrm{P}, 0.01 \% \div 0.03 \% \mathrm{Cr}$, $0.01 \% \div 0.03 \% \mathrm{Ni}, 0.01 \% \div 0.03 \% \mathrm{Cu}, 0.01 \% \div 0.03 \%$ Mo. Depending on the conditions of the investigations, melts with sulphur content at the level of $0.02 \%$ or $0.08 \%$ were prepared.

Test melts were prepared according to the following procedure: the charge after melting was overheated to $1490{ }^{\circ} \mathrm{C}$ and held at that temperature for about 100 seconds; the additional inoculating compounds, i.e. Fe powder and disintegrated steel scrap, were added to molten alloy at the temperature of $1460{ }^{\circ} \mathrm{C}$. Then, when the temperature dropped to $1410{ }^{\circ} \mathrm{C}$, the SB5 master inoculant was introduced. Standard test bars of $\phi 30 \times 260 \mathrm{~mm}$ were cast. From these bars, the specimens for the tensile test and for the metallographic examinations were prepared by turning. Metallographic examinations were carried out under a LEICA MEF4M optical microscope.

\section{RESULTS AND DISCUSSION}

During investigations nine melts were made. Their characteristic is given in Table 1. Figure 1 shows microstructures of cast iron from melts Nos. 1 and 2. Photographs shown in Figure 1a, b prove that, besides the dendrites of reacted austenite, the prevailing constituent is cementite eutectic. The precipitates of austenite have different degree of dispersion. The above effect may be due to the presence of Fe powder. Carried out in this way, the inoculation results in refinement of the white cast iron structure, as revealed by microstructures examined in Nomarsky contrast (Fig. 1b, d). 
Table 1. Melt specification

\begin{tabular}{|c|c|c|c|c|c|c|}
\hline \multirow{2}{*}{$\begin{array}{l}\text { Melt } \\
\text { No. }\end{array}$} & \multirow{2}{*}{$\begin{array}{c}\text { Sulphur } \\
\text { content, } \\
\text { wt. } \%\end{array}$} & \multirow{2}{*}{ Description of metallurgical treatment } & \multicolumn{4}{|c|}{ Tensile strength UTS, MPa } \\
\hline & & & UTS1 & UTS2 & UTS3 & Mean \\
\hline 1 & 0.08 & base cast iron, plain & - & - & - & - \\
\hline 2 & 0.08 & $\begin{array}{l}\text { base cast iron with addition of Fe powder, } \\
\text { without master inoculant SB5 }\end{array}$ & - & - & - & - \\
\hline 3 & 0.08 & inoculation with SB5 & 251 & 269 & 279 & 266 \\
\hline 4 & 0.08 & adding Fe powder, inoculation with SB5 & 271 & 281 & 288 & 280 \\
\hline 5 & 0.08 & $\begin{array}{l}\text { adding disintegrated steel scrap, } \\
\text { inoculation with SB5 }\end{array}$ & 272 & 285 & 292 & 283 \\
\hline 6 & 0.02 & inoculation with SB5 & 224 & 231 & 238 & 231 \\
\hline 7 & 0.02 & adding Fe powder, inoculation with SB5 & 278 & 282 & 292 & 284 \\
\hline 8 & 0.02 & $\begin{array}{l}\text { adding disintegrated steel scrap, } \\
\text { inoculation with SB5 }\end{array}$ & 264 & 269 & 273 & 269 \\
\hline 9 & 0.02 & $\begin{array}{c}\text { physical mixture } \\
\text { (SB5 inoculant and disintegrated steel scrap) }\end{array}$ & 218 & 223 & 231 & 224 \\
\hline 10 & 0.08 & $\begin{array}{c}\text { physical mixture } \\
\text { (SB5 inoculant and disintegrated steel scrap) }\end{array}$ & 260 & 267 & 275 & 267 \\
\hline
\end{tabular}

a)

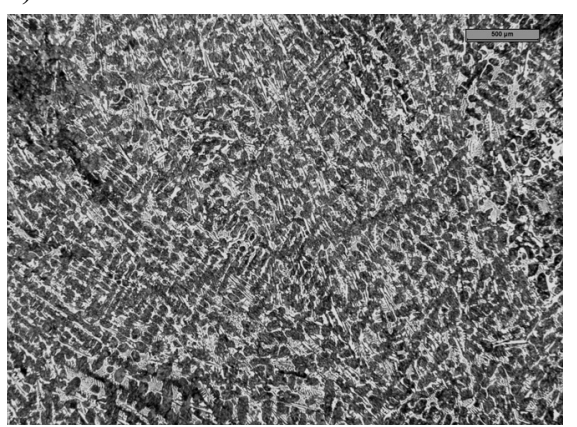

c)

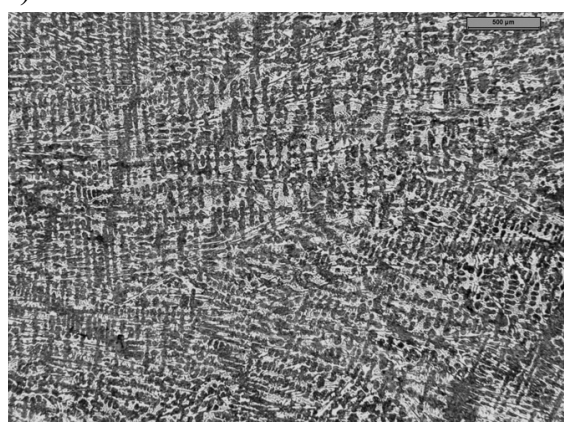

b)

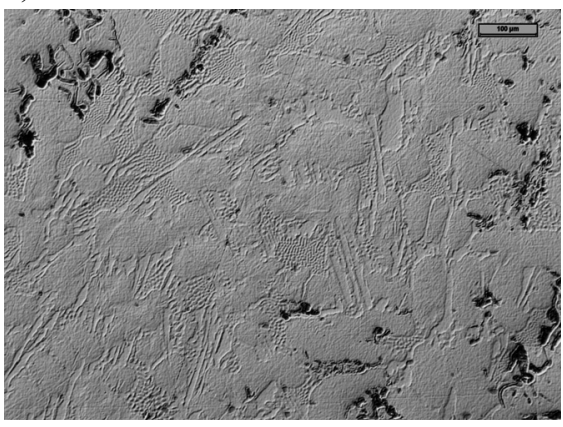

d)

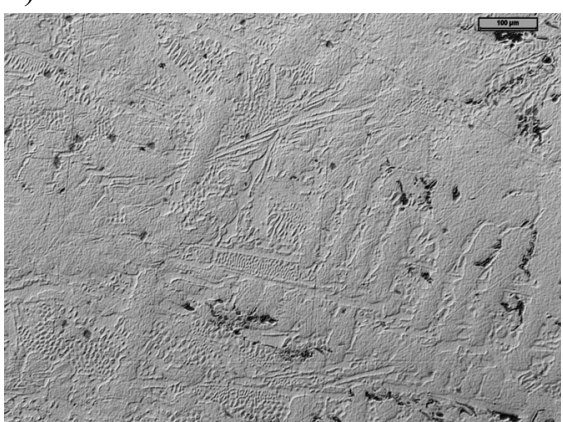

Fig. 1. Microstructures of cast iron from melts No. $1(a, b)$ - different magnification, and No. $2(c, d)$ - different magnification 
a)

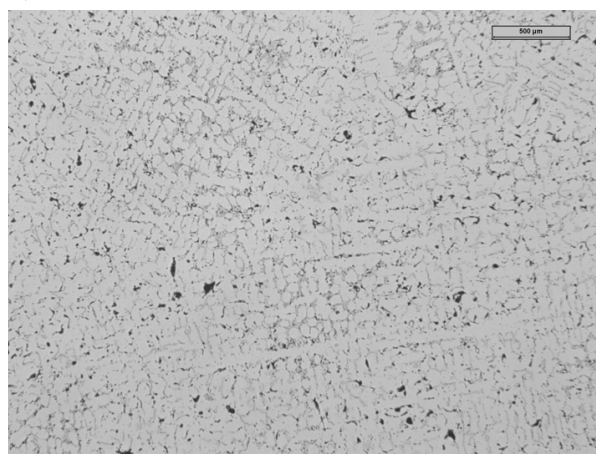

c)

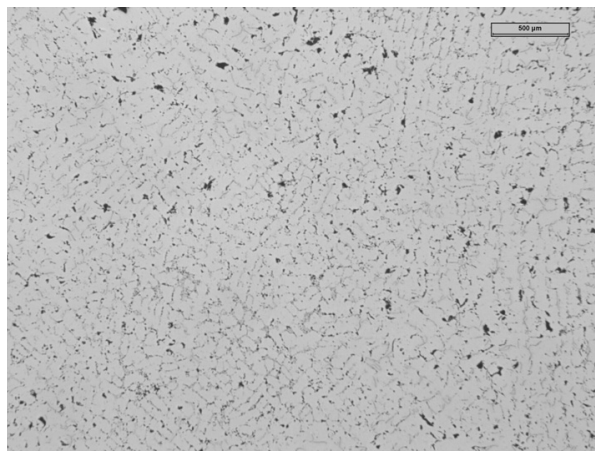

e)

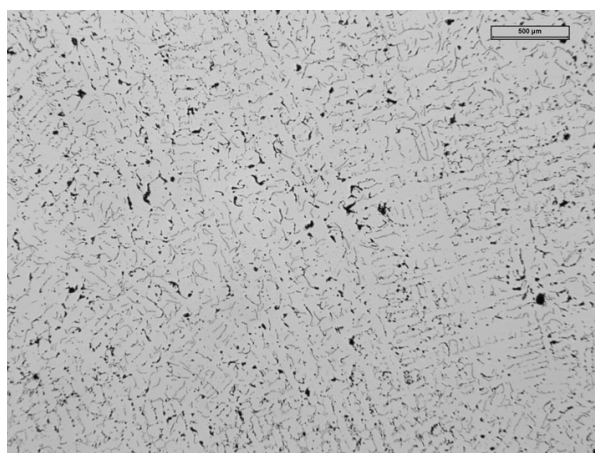

b)

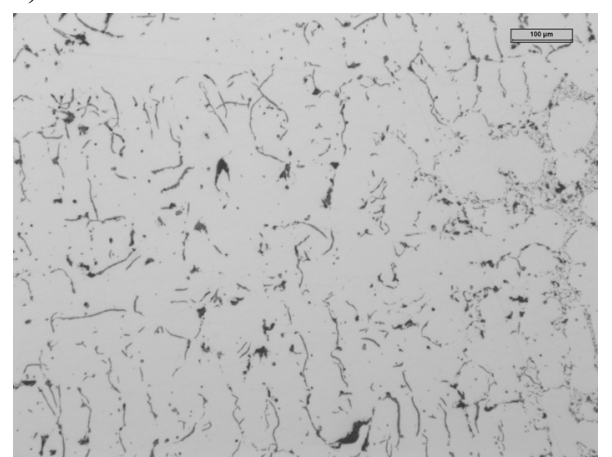

d)

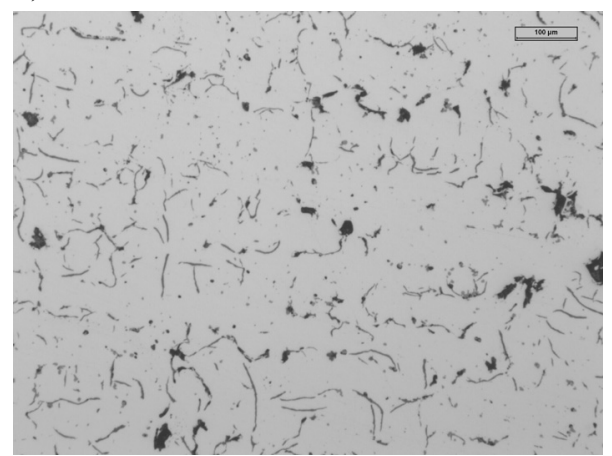

f)

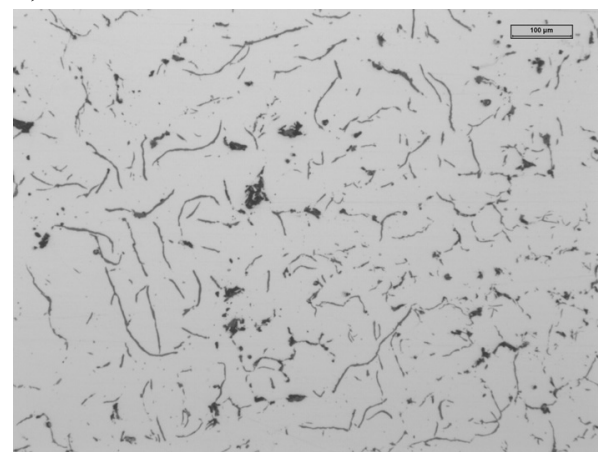

Fig. 2. Graphite distribution in iron casting microstructure produced from melts No. $3(a, b)$, No. 4 $(c, d)$ and No. $5(e, f)$ - different magnification

It is worth noting that the investigated cast iron is characterised by low degree of eutectic saturation $\mathrm{S}_{\mathrm{c}}$, which in this alloy amounts to about $0.81\left\{\mathrm{~S}_{\mathrm{c}}=\mathrm{C} /(4.26-0.3 \mathrm{Si}-0.36 \mathrm{P}\}\right.$. The inoculation carried out with SB5 master inoculant produces in cast iron microstructure the graphite of type E (acc. to PN-EN ISO 945), as shown in Figure 2 a, b. Adding besides SB5 inoculant also Fe powder and disintegrated steel scrap did not change the graphite precipi- 
tates characteristic (Fig. 2c, d, e, f), though slight increase of the tensile strength UTS has been reported (see Tab. 1) and also shown in Figure 3 (cast iron containing 0.08\% sulphur). It has also been stated that adding Fe powder indirectly affects the number of graphite eutectic grains, increasing it slightly (Fig. 4). This effect may be due to an increased number of the austenite grains and smaller dendrite arm spacing, leaving less free space for the solidification of graphite eutectic grains.

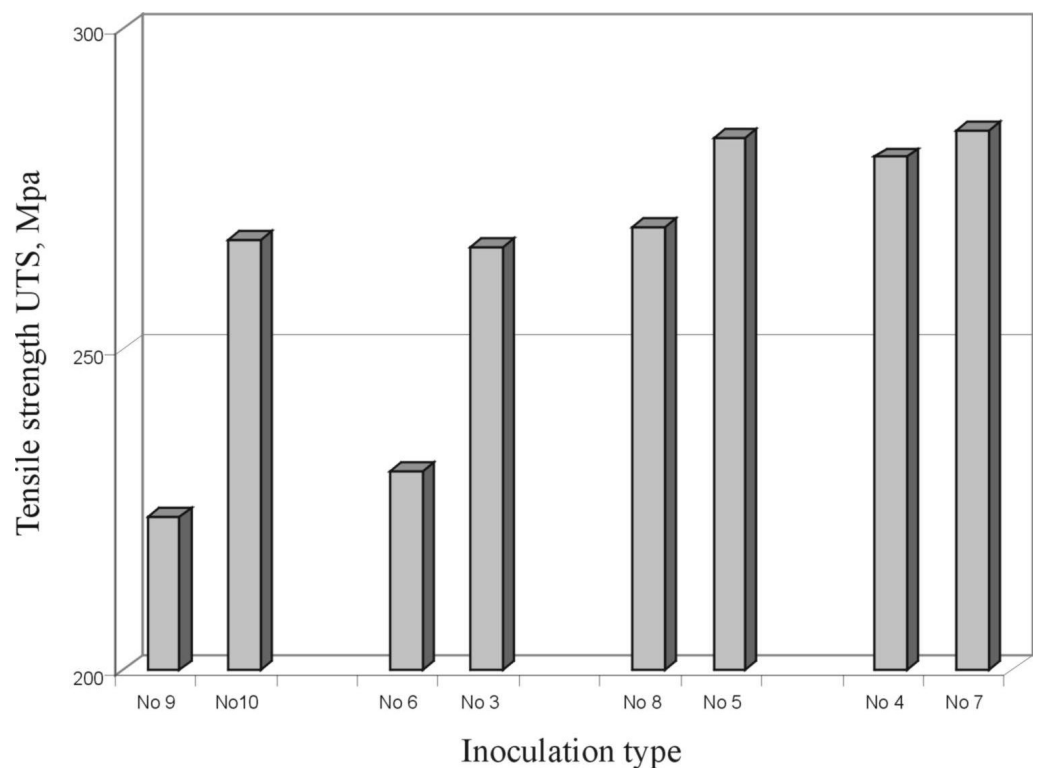

Fig. 3. Sulphur content and inoculation type vs tensile strength UTS of cast iron

a)

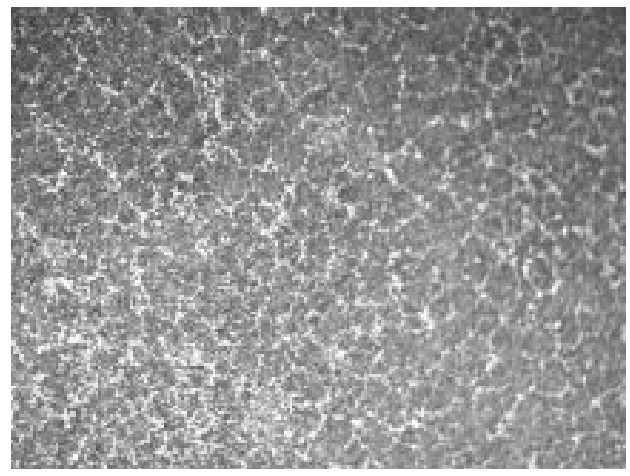

b)

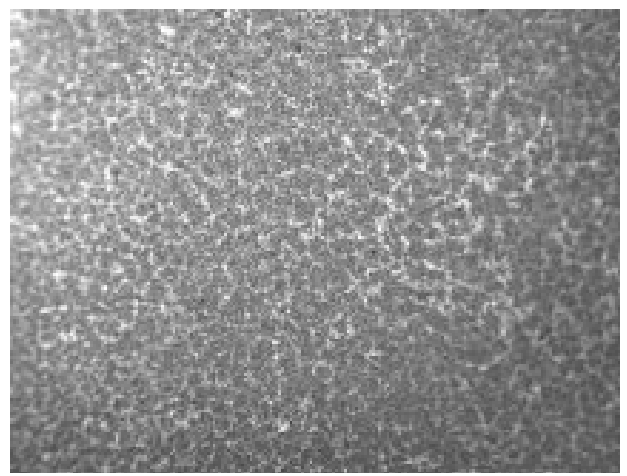

Fig. 4. Number of graphite eutectic grains in the structure of cast iron from melts No. 3 (a) and No. 4 (b) - magnification $10 \times$ 
From the results of the investigations compared in Table 1 and Figure 4 it follows that sulphur drop in cast iron after inoculation considerably reduces the tensile strength $R_{m}$ (melts Nos. 3 and 6 in Tab. 1). Introducing additional inoculants, i.e. Fe powder or disintegrated steel scrap, to molten alloy shortly before pouring of mould improves the mechanical properties (melts Nos. 7 and 8 in Tab. 1 and Fig. 4).

a)

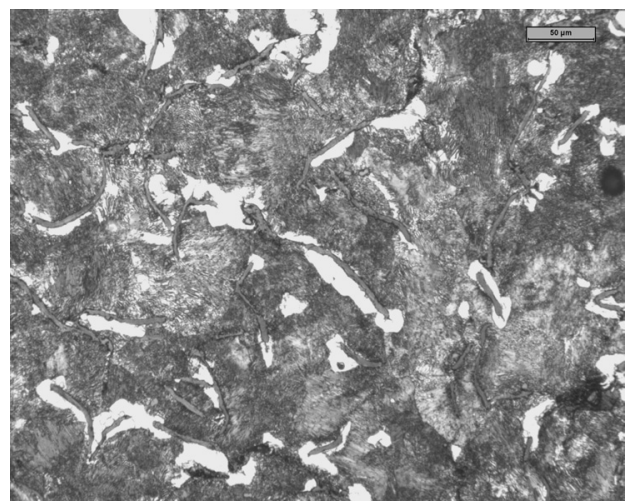

c)

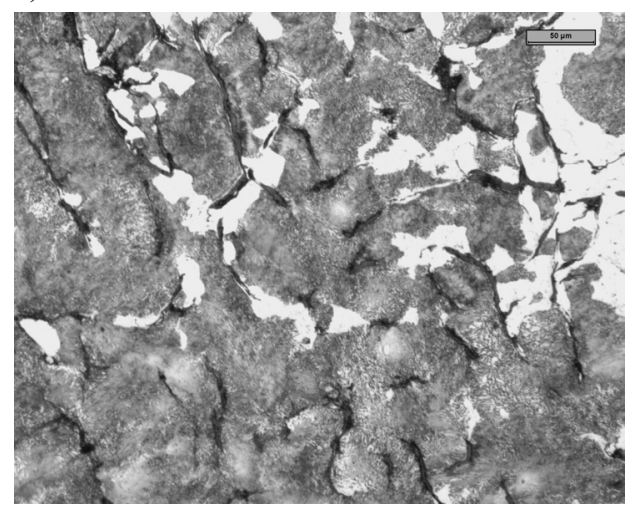

b)

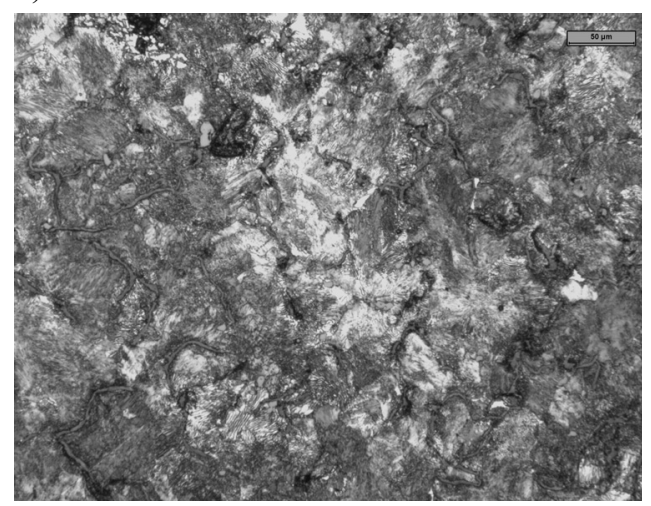

d)

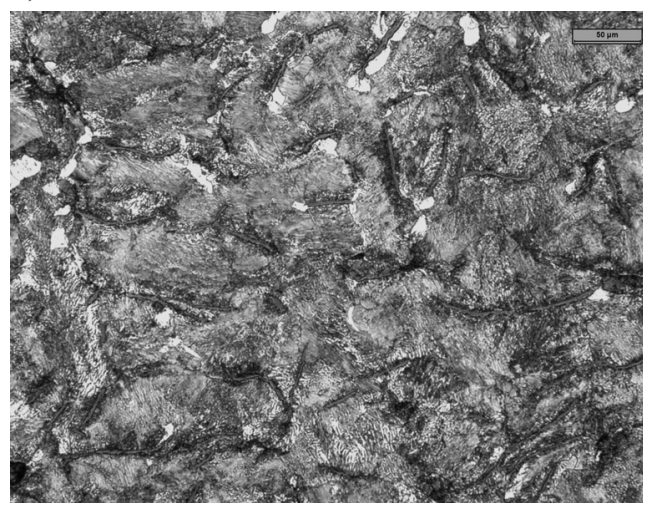

Fig. 5. Matrix of iron casting structure produced from melts No. 3 (a), No. 4 (b), No. 6 (c) and No. 7 (d)

Microstructures of the examined cast iron shown in Figure 5 prove the existence of pearlitic matrix in the structure of cast iron after an additional treatment, i.e. with Fe powder. Similar structure was obtained after an addition of the disintegrated steel scrap. From the microstructure of cast iron shown in Figure 6 it follows that in this case the precipitates of graphite are of an interdendritic character and type E (acc. to PN-EN ISO 945), which sounds logical considering the small dendrite arms spacing, smaller than the interlamellar spacing in graphite eutectic. 
a)

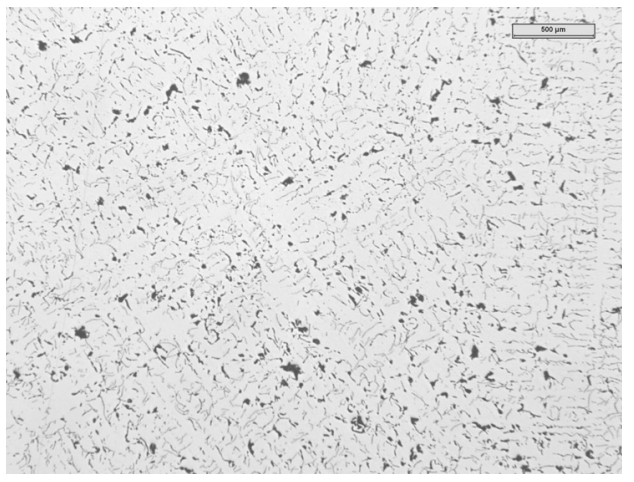

c)

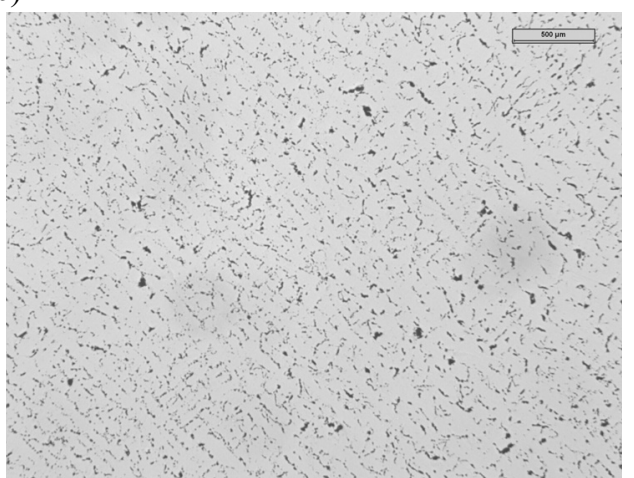

e)

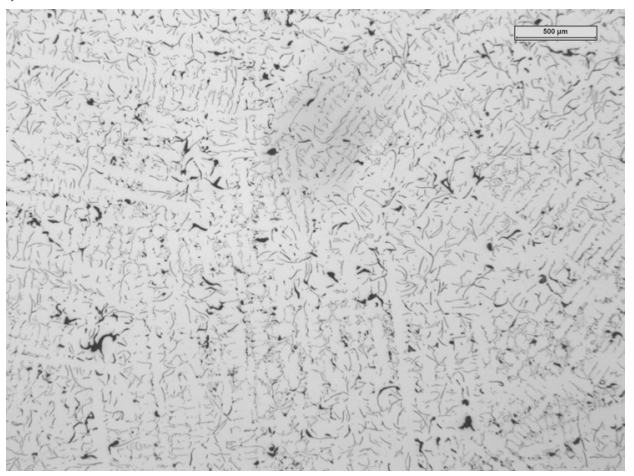

b)

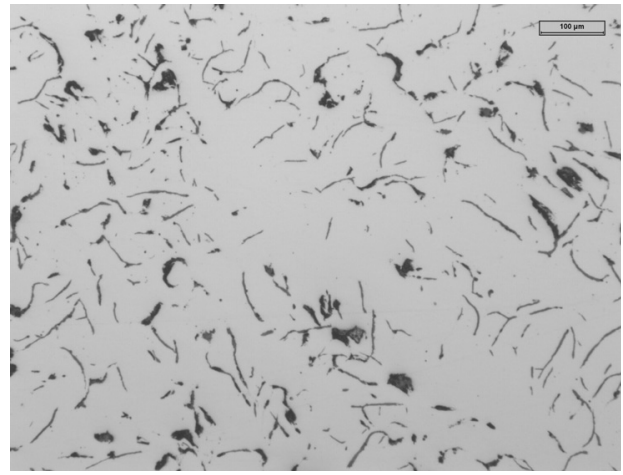

d)

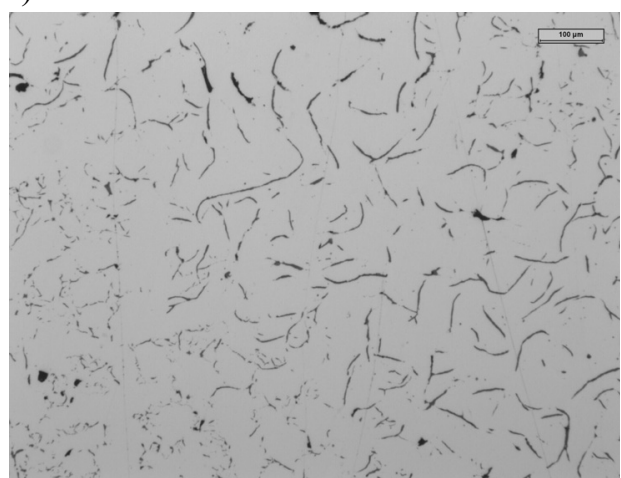

f)

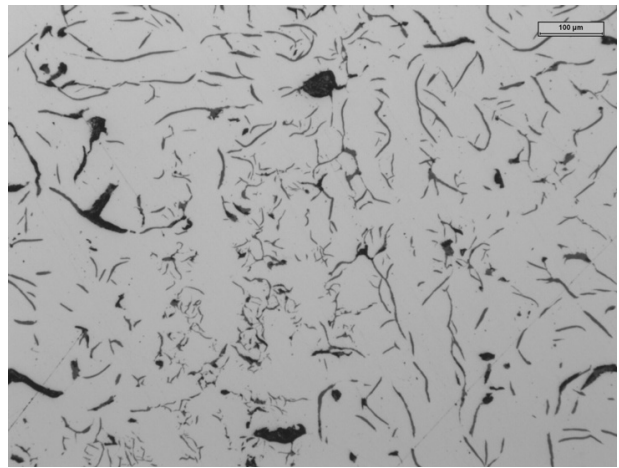

Fig. 6. Graphite distribution in iron casting structure produced from melts No. $6(a, b)$, No. 7 (c, $d)$ and No. $8(e, f)$; - different magnification

\section{CONCLUSIONS}

It is the fact generally known that the recommended sulphur content in inoculated grey cast iron should be comprised in a range of $0.05 \% \div 0.08 \%$, as only this range quarantines 
effective inoculation. Foundries nowadays run short of process scrap, which is the main cause of problems as regards obtaining the above mentioned sulphur content levels in the metallic charge and, consequently, in the base cast iron used for inoculation. To obtain the expected effects of inoculation, the content of sulphur is usually made up by adding sulphur compounds to the melt. The present study proves that there is another solution of this problem, which consists in introducing disintegrated steel scrap before the inoculation treatment. This operation increases the number of solidification nuclei of the dendrites of primary autenite, as suggested by the authors in [10]. In this case, the iron particles act as substrates for the nucleation of primary austenite $\gamma_{p}$ due to a similar crystallographic behaviour of the regular face centered cubic lattice. The more numerous are the dendrites of primary austenite, the less free space is available in the interdendritic spaces for the formation of graphite eutectic grains, which makes the structure more refined (more eutectic grains) and the mechanical properties higher.

So, the conclusion is that by introducing to low-sulphur cast iron the disintegrated steel scrap still before the inoculation carried out with a conventional graphitising inoculant, the mechanical properties similar to those obtained during the inoculation of cast iron with a recommended high sulphur level are achieved.

\section{REFERENCES}

[1] McClure N.C., Khan A.U., McGrady D.D., Womohel H.L.: Inoculation of grey cast iron, Transactions AFS. 65, 1957, 340-349

[2] Merchant H.D., Toriello L.J., Wallace J.F.: Inoculation influence on grey cast iron structure at various carbon equivalences, Modern Castings. 33, 1961, 109-116

[3] Filkins W.C., Stuhrke W.F., Matter D., Wallace J.F.: Grey cast iron inoculation and inoculants evaluation, Transactions AFS. 70, 1963, 882-895

[4] De Sy A.: Oxygen, oxides, superheating and graphite nucleation in cast iron, Modern Castings, 52, 1967, $67-78$

[5] Lux B.: Nucleation and graphite in Fe-C-Si alloys, in Recent Research on Cast Iron, Gordon and Breach, 1968 New York - London - Paris

[6] Fraś E., Lopez H.F., Podrzucki C.: The influence of oxygen on the inoculation process of cast iron, Int. J. Cast Metals Research, 13, 2000, 107-121

[7] Olsen S.O., Skaland T., Hartung C.: Inoculation of grey and ductile iron a comparison of nucleation sites and some practical advises, Elkem ASA, Foundry Products Division, 14-th International Baltic Conference Materials Engineering'2005

[8] Dugic I., Dioszegi A., Svenson I.L.: The influence of inoculation on the metal expansion penetration with respect to the primary and eutectic solidification, Research report. School of Engineering - Jonkoping University, 2005, 1-22

[9] Riposan I., Chisamera M., Stan S., Skaland T., Onsoien M.: Analysis of possible nucleation sites in $\mathrm{Ca} / \mathrm{Sr}$ over-inoculated grey cast irons, Transactions AFS, 2001, 109, 1151-1162

[10] Dioszegi A., Liu K.Z., Svensson J.L.: Inoculation of primary austenite in grey cast iron, Cast Metals Research, 2007, 20, 2, 68-72

Received

October 2010 